\title{
Stress and Fatigue Management Using Balneotherapy in a Short-Time Randomized Controlled Trial
}

\author{
Lolita Rapolienè, ${ }^{1,2}$ Artūras Razbadauskas, ${ }^{3,4}$ Jonas Sąlyga, ${ }^{2,3}$ and Arvydas Martinkènas ${ }^{5}$ \\ ${ }^{1}$ Klaipeda Seamen's Health Care Center, Taikos Street 46, LT-91213 Klaipeda, Lithuania \\ ${ }^{2}$ Department of Nursing of Klaipeda University, H. Manto Street 84, LT-92294 Klaipeda, Lithuania \\ ${ }^{3}$ Klaipeda Seamen's Hospital, Liepojos Street 45, LT-92288 Klaipéda, Lithuania \\ ${ }^{4}$ Faculty of Health Science, Klaipėda University, H. Manto Street 84, LT-92294 Klaipėda, Lithuania \\ ${ }^{5}$ Department of Statistics, Klaipeda University, H. Manto Street 84, LT-92294 Klaipėda, Lithuania \\ Correspondence should be addressed to Lolita Rapolienè; lolita.rapoliene@inbox.lt
}

Received 29 November 2015; Revised 2 February 2016; Accepted 4 February 2016

Academic Editor: Antonella Fioravanti

Copyright (C) 2016 Lolita Rapolienè et al. This is an open access article distributed under the Creative Commons Attribution License, which permits unrestricted use, distribution, and reproduction in any medium, provided the original work is properly cited.

\begin{abstract}
Objective. To investigate the influence of high-salinity geothermal mineral water on stress and fatigue. Method. 180 seamen were randomized into three groups: geothermal (65), music (50), and control (65). The geothermal group was administered $108 \mathrm{~g} / \mathrm{L}$ salinity geothermal water bath for 2 weeks five times a week. Primary outcome was effect on stress and fatigue. Secondary outcomes were the effect on cognitive function, mood, and pain. Results. The improvements after balneotherapy were a reduction in the number and intensity of stress-related symptoms, a reduction in pain and general, physical, and mental fatigue, and an improvement in stress-related symptoms management, mood, activation, motivation, and cognitive functions with effect size from 0.8 to 2.3. In the music therapy group, there were significant positive changes in the number of stress symptoms, intensity, mood, pain, and activity with the effect size of 0.4 to 1.1. The researchers did not observe any significant positive changes in the control group. The comparison between the groups showed that balneotherapy was superior to music therapy and no treatment group. Conclusions. Balneotherapy is beneficial for stress and fatigue reduction in comparison with music or no therapy group. Geothermal water baths have a potential as an efficient approach to diminish stress caused by working or living conditions.
\end{abstract}

\section{Introduction}

Stress is an important contributing factor to an individual's quality of life, and high levels of stress, if not managed, can negatively affect an individual's emotions, health, and implicit well-being [1-3]. Stress is linked to the six leading causes of death: heart disease, accidents, cancer, liver disease, lung ailments, and suicide [1]. It is also associated with an individual's absenteeism from work, increased medical expenses, loss of productivity, insomnia, fatigue, cognitive impairment, depression, and other mental or neurological illnesses, hypertension, arthritis, ulcers, asthma, migraines, immune system disturbances, skin diseases, aggression and relational conflict, and substance abuse and increases the negative effects of aging [3-6].

Stress can be caused by noise, vibrations, heat, improper lighting, and rapid acceleration in an individual's work pace, anxiety, fatigue, frustration, and anger [1,2]. Stress is the second most frequently reported work-related health problem after musculoskeletal diseases, affecting $22 \%$ of workers in the European Union (EU) and accounting for $50-60 \%$ of all lost working days, with an annual cost of 20 billion Euro in 2002 (EU-15) [7]. Stress is widespread among health care and education workers and among other white-collar workers and seafarers [7-10]. Seafaring is a dangerous and challenging profession worldwide and is associated with a high level of work-related stress [11-13]. In the EU, prevention of workrelated stress is one of the most important new strategies for health and safety at work [14].

Stress has a direct association with fatigue and health [2]. The prevalence of fatigue in the general working population has been estimated to be as high as $22 \%$, and this fatigue is associated with pain, tiredness, nervous system mechanisms, and environmental stimuli in individuals who experience 
the effects $[1,15]$. The effects of fatigue are multifaceted and complex, overlapping various biological areas such as performance, physiology, cognition, and emotion [1].

Health promotion and disease prevention are more important than ever in societies with increasing life expectancy and growing stress levels. Health promotion measures can help prevent the onset of a disease and may have a beneficial effect on the course of the disease, thus contributing to healthy aging with good quality of life [16]. Numerous approaches are available for stress and fatigue management that can decrease patients' suffering from stress and fatigue and enhance their quality of life, but no single approach fits for all individuals. Stress model demonstrates the favorable effects exhibited by sleep, recovery, and social support [2]. It has been proven that relaxation techniques such as behavioral therapy, meditation, yoga, breathing techniques, reflexology, massage, Reiki, water therapy, and others are beneficial for stress reduction [11, 17-21]. Specifically, a technique called music therapy involves the use of music therapeutically to address physical, psychological, cognitive, and/or social functioning for patients of all ages. According to researchers, music therapy improves human psychological conditions, reduces symptoms of anxiousness and depression, and treats long-term stress-related physical ailments $[12,17,19]$.

Balneotherapy (lat. balneum - bath + gr. therapeia - treatment, nursing) involves using natural mineral spring water for the prevention and cure of disease. The World Health Organization recognizes the therapeutic impact of medicinal mineral waters, thermal or nonthermal [20]. Natural mineral water is a general term applied to both spring and other underground continental waters (from deep-seated waterwells). Because of high temperature and mineralization, geothermal water can serve people from various economical areas for improving health during balneotherapy procedures $[13,22]$. Natural mineral water has been considered a curative tool for millennia, having well-known healing properties in terms of prevention, treatment, and rehabilitation of skin, musculoskeletal, cardiovascular, endocrine, nervous, and other human body systems [11, 16, 20, 23-28]. During the last 30 years, a number of controlled trials have demonstrated the efficacy of balneotherapy in treating certain diseases, mostly musculoskeletal conditions [16, 25, 27, 29].

The essence of balneotherapy effects (including antistress) are local changes caused by the direct influence of mechanical, thermal, and chemical factors through the skin and mucous membranes and complex adjustment reactions as a result of neuroreflexive, humoral mechanisms, caused by stimulation of mechano-, thermo-, baro-, and chemoreceptors by biochemical active substances during the balneoprocedure [21, 30-36].

Researchers in balneotherapy studies commonly used mineral water of $0.6-31.9 \mathrm{~g} / \mathrm{L}$ total mineralization, excluding studies in the Dead Sea [22, 23, 25, 28, 33-35, 37-39]. We performed the study with $108 \mathrm{~g} / \mathrm{L}$ TDS in order to increase the effectiveness for the general working population. To our knowledge, there have not been any trials with such a high salinity of thermal water. This study may be the first published in English applying such a highly concentrated brine application in which the mineral age of the water is not less than 1 million years.

The objective of our study was to investigate the influence of high-salinity geothermal mineral water from artificial sources on seamen's stress and fatigue and to find an effective measure of health protection and restoration for individuals working in highly stressful occupations.

\section{Patients and Methods}

This prospective open-label randomized controlled parallelgroup biomedical trial was implemented in observance of the rules of good clinical practice; our research protocol was approved by the Kaunas Regional Biomedical Research Ethics Committee (Approval number BE-2-31/2012). All subjects were informed about the purpose, conditions, and course of the study prior to the inclusion and signed a participant's agreement.

This study was conducted in Klaipeda, Lithuania, during September-November, 2012. The target population consisted of working seamen from Klaipeda region (Lithuania), recruited and examined by a trained independent general practitioner (GP) during a medical examination at a Sea Center in the Seamen's Hospital and Seamen's Health Care Center in Klaipeda city. Out of the 220 seamen, 180 met inclusion criteria and agreed to participate in the study and were subject to a randomization procedure. Inclusion criteria were as follows: male seamen, aged 25-64, and working at sea for more than 5 years, stress and fatigue intensity level more than 2 (visual analogue scale (VAS) from 0 to 10). Our exclusion criteria were related to the following symptoms: acute organic neurological deficit, neoplastic or inflammatory lesion, decompensated cardiovascular disease, unstable metabolic disorders, febrile infections, and cutaneous suppuration.

After the completion of survey for sociodemographic, work-related, and clinical data, 180 subjects were randomized into three groups: the balneotherapy group (65), the music therapy group (50), and the control group (65). The disposition of the participants is shown in Figure 1. The randomization was simple, with generation of random numbers. The generation of random number order was performed by a professional using the SPSS v. 21 software package. The independent professional performing the statistical analysis was aware of the randomization. The enrolled patients completed the balneotherapy and music therapy treatments as outpatients, with no change in their daily routine or work attendance. The same instructions were made for the participants of the control group. The side effects of balneotherapy were supposed to be evaluated by the physician supervising the treatments by means of an observational sheet, side effects of music therapy, in self-administered observational sheets.

The numbers of participants included in the analysis were as follows: in the geothermal group, 55 subjects were analyzed in order to determine the influence of the therapy on stress and fatigue, as well as its effect on the cardiopulmonary system, mood, and pain; in the music therapy group, data from 35 subjects were studied, and, in the control group, 50 participants were analyzed. 


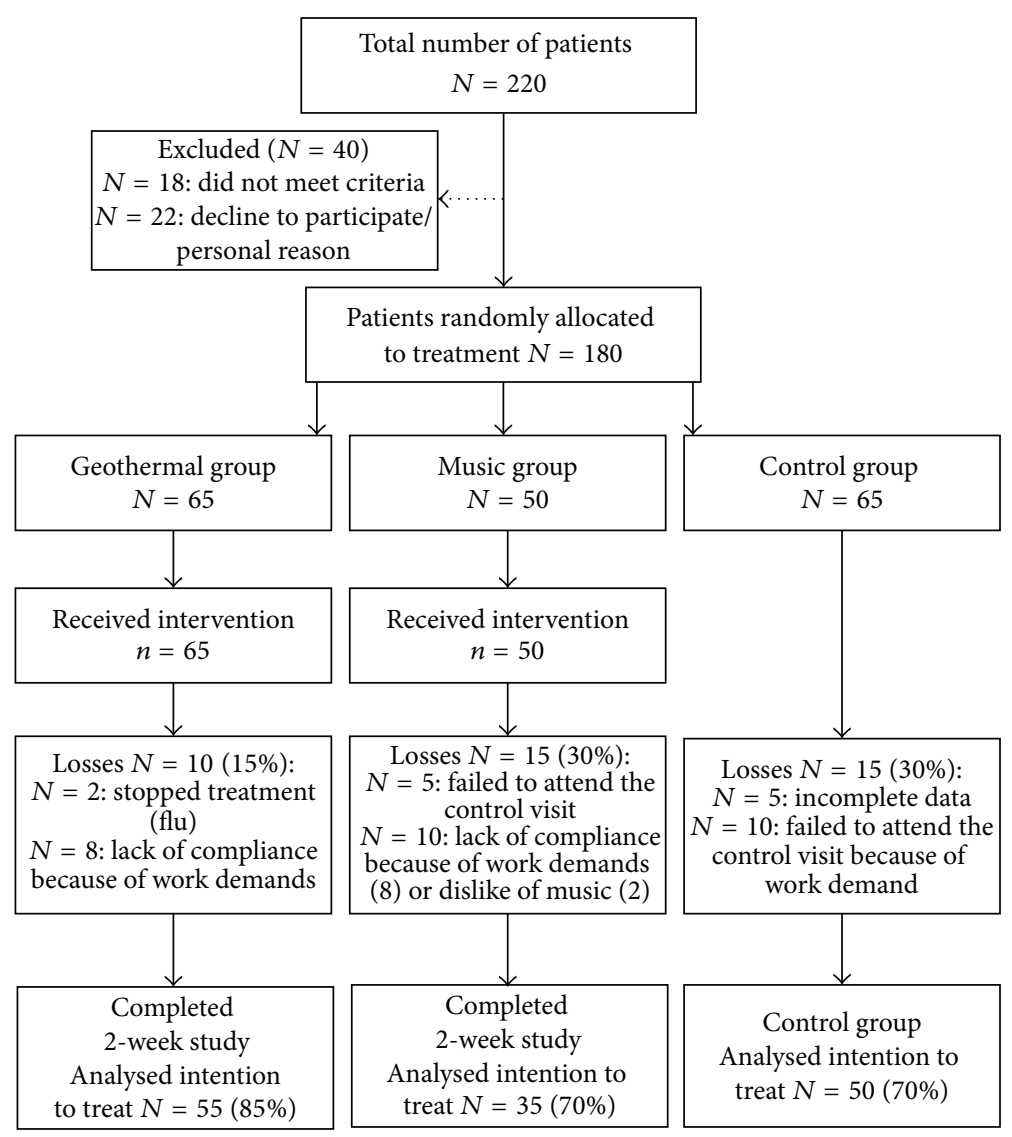

FIGURE 1: Disposition of the study participants.

The balneotherapy group was administered a head-out immersion bath with naturally warm $\left(34.6^{\circ} \mathrm{C}\right.$ on average) highly mineralized $(108 \mathrm{~g} / \mathrm{L})$ geothermal $\mathrm{Na}-\mathrm{Cl}-\mathrm{Ca}-\mathrm{Mg}-\mathrm{SO}_{4}$ mineral water with a $\mathrm{pH} 6.07$ from a "Geoterma2P" borehole (1135 m depth, Lower Devonian layer, mineral age of more than 1 million years). Volumetric activity of radon in the water was $29 \pm 5 \mathrm{~Bq} / \mathrm{L}$. The water chemical composition is shown in Table 1.

The subjects underwent balneotherapy sessions for $15 \mathrm{~min}$ daily, five times a week, for 2 weeks, and were monitored continuously during the treatment sessions by trained personnel. Each participant was told to move slightly in the bathtub during the procedure. After the baths, participants were recommended to gently dry the skin with a towel and not to shower for about one hour to prolong the effects of the procedure [20]. The study protocol required that participants attend at least $60 \%$ of treatments or a minimum of 6 balneotherapy sessions. We performed ten procedures of music therapy at home with Peter Huebner's Medical Resonance Therapy Music ${ }^{(}$(RRR 932 General Stress) [40]. We used the receptive intervention of music therapy, which asks participants to listen to music, allowing them to become recipients of the musical experience. We used standardized music therapy procedures approved by the Rehabilitation Department of Klaipeda Seamen's Hospital and recommended by Medical Resonance Therapy Music, which involve treatment through the following process: 20 minutes of sitting or lying down with closed eyes and earphones and avoiding disturbances from outside noise. The participants were trained for the music therapy procedure and for blood pressure and heart rate measurement. They were given selfobservational protocols and were asked to record any changes in their general feelings after the procedure. Adherence to the self-administered music therapy protocol was controlled by daily telephone calls.

Baseline and posttherapy assessments of all three groups were performed by a trained GP. The GP's evaluation consisted of overall reported health, medication use, evaluation of pain using visual analogue scale (VAS) from 0 to 10 (0 $=$ no pain; $10=$ worst imaginable pain), mood according to Likert's 5-point scale ((1) bad, (2) satisfactory, (3) good, (4) very good, and (5) perfect mood), systolic and diastolic blood pressure ( $\mathrm{mmHg}$ ), and heart and respiratory rates (time/min) as changes in feelings and side effects. Stress and fatigue were assessed by the self-administered general symptoms distress scale (GSDS) [41], the Multidimensional Fatigue Inventory (MFI) [42], and the Cognitive Failures Questionnaire (CFQ) [43].

The primary outcome measures were as follows. (1) First is the change of distress level in the GSDS between baseline and posttreatment evaluations. The GSDS (T. Badger, Arizona, USA) was chosen due to its adequate internal consistency, reliability, good constructional and prognostic validity, and good correlation with depression and positive and negative 
TABLE 1: The mineral composition of geothermal water.

\begin{tabular}{lc}
\hline Element & Concentration, mg/L \\
\hline $\mathrm{Cl}^{-}$ & 66930 \\
$\mathrm{Na}^{+}$ & 27580 \\
$\mathrm{Ca}^{2+}$ & 8990 \\
$\mathrm{Mg}^{2+}$ & 2630 \\
$\mathrm{SO}_{4}{ }^{2-}$ & 1330 \\
$\mathrm{~K}^{+}$ & 690 \\
$\mathrm{HCO}_{3}{ }^{-}$ & 74 \\
$\mathrm{Br}^{2}$ & 60.62 \\
$\mathrm{~N}$ & 22 \\
$\mathrm{Fe}^{2}$ & 12.14 \\
$\mathrm{~B}$ & 6.501 \\
$\mathrm{Si}^{4+}$ & 4.886 \\
$\mathrm{Li}^{+}$ & 1.2 \\
$\mathrm{Cr}^{2}$ & 1 \\
$\mathrm{~F}^{-}$ & 0.91 \\
$\mathrm{Mn}^{2+}$ & 0.501 \\
$\mathrm{H}_{2} \mathrm{~S}$ & 0.33 \\
$\mathrm{Cu}^{2+}$ & 0.167 \\
$\mathrm{Zn}^{2+}$ & 0.062 \\
$\mathrm{Total}^{2+}$ amount of dissolved mineral & $\mathbf{1 0 8 3 3 4}$ \\
substances (TDS), mg/L & \\
\hline &
\end{tabular}

affects [41]. This short psychometric tool allows for assessing specific distress symptoms and evaluating their intensity and control on a 10-point scale. (2) Second is the changes in fatigue scores (MFI). The MFI is a 20 -item self-report instrument designed to measure fatigue. It covers the following dimensions: general fatigue, physical fatigue, mental fatigue, reduced motivation, and reduced activity. The use of this instrument offers the opportunity to obtain a profile of fatigue [42]. The secondary outcome measures of the study included such self-assessment scales as CFQ, mood and pain scales, changes in the cardiopulmonary system (blood pressure, heart rate, and respiration rate), and medication use.

The sample size was estimated using the IBM SPSS Sample Power Release software v. 3 for the stress outcome using the general symptoms distress scale (GSDS). We examined mean differences between balneotherapy and the control groups. We estimated that the sample size in both groups should be 32 subjects, with the power of $81.7 \%$ to achieve a statistically significantly different result. This computation assumes that the mean difference in the general symptoms distress between the balneotherapy and the control or the music therapy groups would be not less than 0.8 , and the standard deviation within the groups would be 1.1. This effect was selected as the least significant effect of detectable importance; any smaller effect would not be of clinical or substantive significance. We assumed that the influence of balneotherapy and music therapy on the difference in the mean values of the variables is valid because such changes during the procedures are fully probable in this field of research. The mean difference of the observed variables of 0.8 (1.1) would be presented with a $95 \%$ CI of 0.25 to 1.35 .

\section{Statistical Analysis}

A descriptive analysis (mean, standard deviation (SD), frequencies, and percentages) was used to examine the participants' background, demographic variables, and treatments. Data were presented with mean (SD). Data distribution was assessed by applying the Kolmogorov-Smirnov test.

We used the parametric criteria and Student's $t$-test to determine mean differences between two groups; the ANOVA with Bonferroni difference test was applied for multiple comparisons if equal variances were assumed, and Tamhane's $T^{2}$ multiple comparison test was used if equal variances were not assumed between the three groups. Due to the nonnormality of the distribution of the variables, nonparametric methods (the Mann-Whitney test) were used in statistical analyses. The categorical variables between the groups were compared using the chi-squared $\left(\chi^{2}\right)$ and Fisher's exact test. $p$-values less than 0.05 were interpreted as statistically significant.

Paired effect sizes before and after the treatment in the groups were estimated with a $95 \%$ confidence interval (CI).

The results were evaluated by applying the intention-totreat analysis (ITT).

The data were analyzed using SPSS (version 21.0; SPSS Inc., Chicago, IL, USA) software.

\section{Results}

The subjects' sociodemographic and clinical characteristics and health-related issues are shown in Table 2. All three groups were similar concerning sociodemographic characteristic, working conditions, stress, fatigue, and pain frequency and intensity, the perceived health status, and harmful addictions. Lower body mass indices and lower medication usage, yet higher morbidity, were found in the geothermal group. All groups were similar concerning neurological diseases, and a significantly bigger morbidity in musculoskeletal, gastrointestinal, and urological and ear, nose, and throat (ENT) diseases was seen in the geothermal group (Table 2).

After a 2-week treatment, patients receiving geothermal water therapy showed a significant therapeutic response compared to the control and music therapy groups (Table 3).

The inside-the-group analysis showed significant positive changes in primary and secondary (CFQ, mood, and pain) outcome measures with the large effect size from 0.78 to 2.25 $(p<0.001)$. The biggest effect was observed for decreasing stress symptoms, pain, stress intensity, and general fatigue (Table 3).

A significant positive effect of music therapy was seen in the reduction of stress symptoms (large effect) and the intensity of stress (medium effect) and pain (medium effect), as well as an increase in activity (small effect) and mood (medium effect).

During the inside-the-group analysis, the participants of the control group showed significant negative changes 
TABLE 2: Sociodemographic and clinical characteristic of the participants in groups.

\begin{tabular}{|c|c|c|c|c|}
\hline & Geothermal $(n=55)$ & Music group $(n=35)$ & Control $(n=50)$ & $p$ value \\
\hline Age, years, mean $(\mathrm{SD})^{\mathrm{a}}$ & $47.5(10.6)$ & $47.6(10.7)$ & $46.2(9.3)$ & 0.733 \\
\hline \multicolumn{5}{|l|}{ Education, $N(\%)^{\mathrm{b}}$} \\
\hline Secondary school & $10(19.2)$ & $4(11.8)$ & $4(8.3)$ & \multirow{3}{*}{0.304} \\
\hline College & $26(41.9)$ & $10(29.4)$ & $21(43.8)$ & \\
\hline Higher education & $20(32.3)$ & $18(52.9)$ & $21(43.8)$ & \\
\hline \multicolumn{5}{|l|}{ Marital status, $N(\%)^{\mathrm{b}}$} \\
\hline Single & $8(15.1)$ & $4(11.4)$ & $2(4.1)$ & \multirow{2}{*}{0.590} \\
\hline Married & $36(67.9)$ & $27(77.1)$ & $40(81.6)$ & \\
\hline Work experience, years, mean (SD) ${ }^{\mathrm{a}}$ & $22.5(11.4)$ & $23.1(11.5)$ & $22.4(9.9)$ & 0.950 \\
\hline \multicolumn{5}{|l|}{ Working hours per day, $N(\%)^{\mathrm{b}}$} \\
\hline 8-12 hours & $32(58.2)$ & $19(54.3)$ & $34(68.0)$ & \multirow{4}{*}{0.302} \\
\hline 13-15 hours & $21(38.2)$ & $11(31.4)$ & $12(24.0)$ & \\
\hline 16-18 hours & $1(1.8)$ & $3(8.6)$ & $3(6.0)$ & \\
\hline$>18$ hours & $1(1.8)$ & $2(5.7)$ & 0 & \\
\hline \multicolumn{5}{|l|}{ Resting hours in 24 hours, $N(\%)^{\mathrm{b}}$} \\
\hline 10 hours & $12(21.8)$ & $3(8.6)$ & $8(16)$ & \multirow{4}{*}{0.366} \\
\hline 8 hours & $17(30.9)$ & $15(42.9)$ & $12(24)$ & \\
\hline 6 hours & $20(36.4)$ & $14(40.0)$ & $21(42)$ & \\
\hline$<6$ hours & $6(10.9)$ & $3(8.6)$ & $9(18)$ & \\
\hline Leading work position, $N(\%)^{\mathrm{b}}$ & $19(35.2)$ & $14(46.7)$ & $21(43.8)$ & 0.433 \\
\hline Frequent stress, $N(\%)^{\mathrm{b}}$ & $15(27.3)$ & $10(28.6)$ & $14(28.0)$ & 0.405 \\
\hline Frequent fatigue, $N(\%)^{\mathrm{b}}$ & $20(36.4)$ & $9(25.7)$ & $10(20.8)$ & 0.149 \\
\hline Frequent pain, $N(\%)^{\mathrm{b}}$ & $4(7.3)$ & $1(2.9)$ & $4(8.0)$ & 0.100 \\
\hline Stress intensity, VAS, $\mathrm{cm}$, mean (SD) ${ }^{\mathrm{a}}$ & $3.8(1.6)$ & $3.7(1.9)$ & $3.6(1.7)$ & 0.820 \\
\hline Pain intensity, VAS, cm, mean (SD) ${ }^{\mathrm{a}}$ & $3.1(1.7)$ & $2.9(1.7)$ & $2.4(1.6)$ & 0.131 \\
\hline Fatigue intensity $(0-7), \mathrm{cm}$, mean $(\mathrm{SD})^{\mathrm{a}}$ & $3.4(1.3)$ & $3.3(1.1)$ & $3.3(1.0)$ & 0.746 \\
\hline Insufficient sleep, $N(\%)^{\mathrm{b}}$ & $17(30.9)$ & $8(22.9)$ & $12(24.5)$ & 0.848 \\
\hline BMI, mean $(S D)^{\mathrm{a}}$ & $27.1(3.0)$ & $28.9(3.0)$ & $26.7(5.1)$ & 0.040 \\
\hline Morbidity, $N(\%)^{\mathrm{b}}$ & $51(94.4)^{\mathrm{c}}$ & $28(80.0)^{\mathrm{d}}$ & $34(68.0)^{\mathrm{d}}$ & 0.002 \\
\hline Cardiovascular diseases & $28(50.9)$ & $12(34.4)$ & $16(32.0)$ & 0.103 \\
\hline Musculoskeletal diseases & $48(87.3)^{\mathrm{c}}$ & $19(54.3)^{\mathrm{d}}$ & $29(58.0)^{\mathrm{d}}$ & 0.001 \\
\hline Gastrointestinal diseases & $24(43.6)^{c}$ & $11(31.4)^{\mathrm{c}}$ & $6(12.0)^{\mathrm{d}}$ & 0.002 \\
\hline Neurological diseases & $27(49.1)$ & $14(40.0)$ & $20(40.0)$ & 0.571 \\
\hline Respiratory diseases & $9(16.4)$ & $4(11.4)$ & $4(8.0)$ & 0.419 \\
\hline ENT diseases & $10(18.2)^{\mathrm{c}}$ & $1(2.9)^{\mathrm{c}}$ & $3(6.0)^{\mathrm{d}}$ & 0.031 \\
\hline Urological diseases & $19(34.5)^{\mathrm{c}}$ & $2(5.7)^{\mathrm{d}}$ & $6(12.0)^{\mathrm{d}}$ & 0.001 \\
\hline Medication usage, $N(\%)^{\mathrm{b}}$ & $19(29.7)$ & $20(57.1)$ & $23(46.9)$ & 0.021 \\
\hline Amount of cigarettes per day, units, mean $(\mathrm{SD})^{\mathrm{a}}$ & $13.5(6.2)$ & $10.4(6.3)$ & $14.1(9.3)$ & 0.399 \\
\hline Amount of alcohol units ${ }^{*}$ per week, mean $(S D)^{a}$ & $3.75(3.1)$ & $4.45(5.84)$ & $3.25(2.35)$ & 0.384 \\
\hline Good health state, $N(\%)^{\mathrm{b}}$ & $32(58.1)$ & $20(57.1)$ & $30(60)$ & 0.332 \\
\hline
\end{tabular}

${ }^{a}$ ANOVA test with Bonferroni correction, ${ }^{b}$ chi-squared $\left(\chi^{2}\right)$ test, and ${ }^{c, d} z$-test, between proportions from each other $p<0.05$.

${ }^{*} 1$ unit $=0.5$ pint of beer/lager or a small glass of wine or a pub measure of spirits or a small glass of sherry or port.

in health status concerning stress management, all fatigue dimensions, and cognitive function. No positive changes were seen after 2 weeks (Table 3 ).

Group comparison is as follows. The changes in the intervention groups ( $G$ versus $M$ ) were significant in lowering the number of stress symptoms (medium effect size $0.5,95 \%$ $\mathrm{CI}-0.9$ to -0.05 (bias corrected by Hedges)), decreasing pain intensity (large effect size $0.95,95 \%$ CI -1.4 to -0.5 ), and improving of mood (medium effect size 0.6 , 95\% CI 0.17 to 1.03) (Table 3). No significant differences were found in other stress items as well as some fatigue dimensions between groups because of significant differences in baseline data.

The comparison between the geothermal and the control groups showed a significant positive therapeutic effect in geothermal group on all primary (stress and fatigue) and secondary (mood and pain) outcomes despite certain 


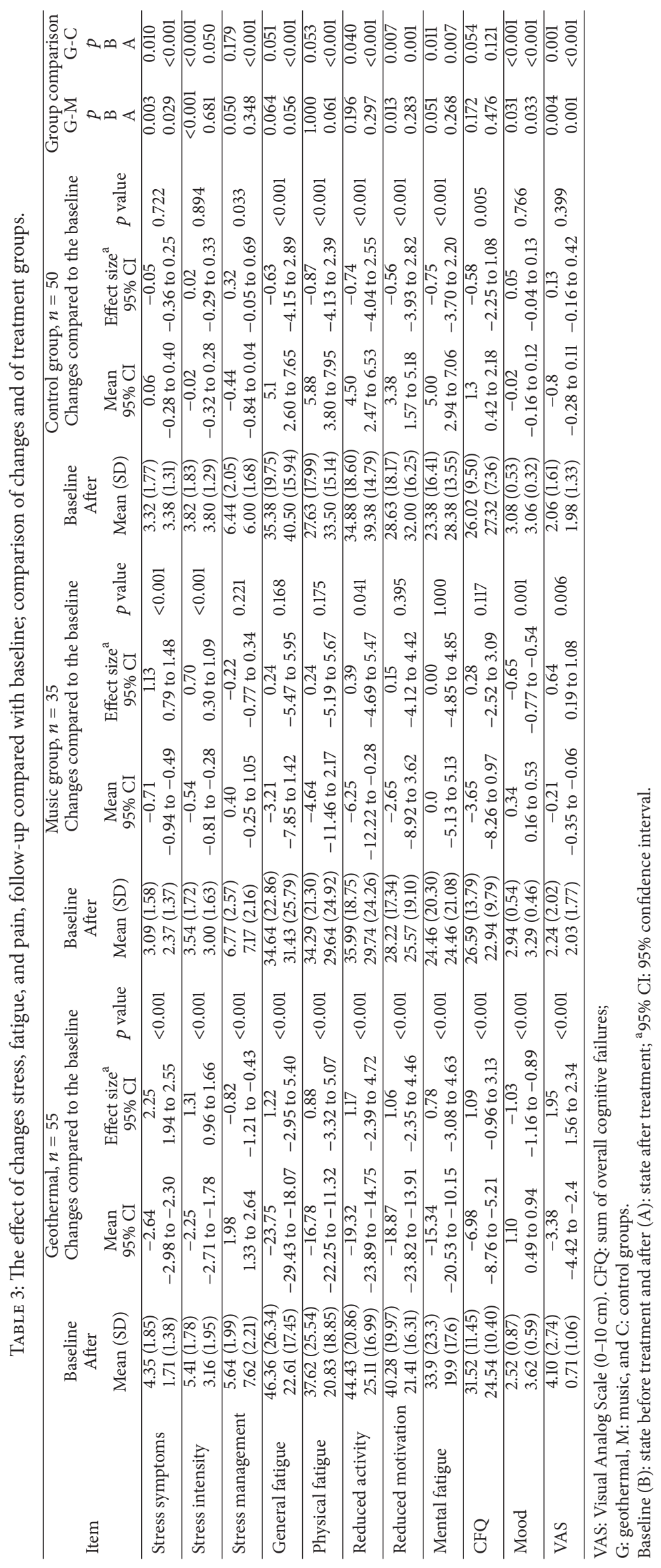


baseline clinical differences between the groups, which were unfavorable to the geothermal group (Tables 2 and 3). Large effect sizes between $\mathrm{G}$ versus $\mathrm{C}$ groups were found in lowering the stress symptoms $(1.2,95 \% \mathrm{CI}-1.65$ to -0.81$)$, pain (1.05, $95 \%$ CI -1.46 to -0.65$)$, and general fatigue $(1.06,95 \% \mathrm{CI}$ -1.47 to -0.65$)$ and in increasing stress management $(0.8$, $95 \%$ CI 0.42 to 1.21$)$, activity $(-0.89,95 \% \mathrm{CI}-1.29$ to -0.48$)$, and $\operatorname{mood}(1.16,95 \%$ CI 0.74 to 1.57$)$; a medium effect size was seen in reducing physical $(0.73,95 \%$ CI 1.13 to -0.34$)$ and mental fatigue $(0.53,95 \% \mathrm{CI}-0.92$ to -0.14$)$ and increasing motivation $(0.65,95 \% \mathrm{CI}-1.04$ to -0.25$)$; and a small effect size was observed for reducing stress intensity $(0.38,95 \% \mathrm{CI}$ -0.77 to 0.01 ).

After 2 weeks of balneotherapy treatment, changes in other study secondary outcomes-cardiopulmonary system parameters-were seen: a reduction of systolic (from 136.4 to $129.5 \mathrm{mmHg}$; mean difference, $7 \mathrm{mmHg}$; CI 3.03 to 11.7; $p=$ 0.001 ) and diastolic (from 84.3 to $78 \mathrm{mmHg}$; mean difference, $6 \mathrm{mmHg}$; CI 3.22 to $8.06 ; p<0.001$ ) blood pressure, heart rate (from 87.3 to $72.4 \mathrm{bpm}$; mean difference, $15 \mathrm{bpm}$; CI 1.03 to $5.0 ; p=0.004$ ), and respiratory rate (from 15.7 to 14.3 times/min; mean difference, 1.4 times $/ \mathrm{min}$; CI 0.47 to $1.7 ; p=$ 0.001 ), while in the music therapy group, only the respiratory rate was significantly reduced (from 15.6 to 14.7 times/min; mean difference, 0.9 times/min; CI 0.23 to $1.49 ; p=0.009$ ). No significant changes were seen in the control group. The differences between the groups were significant $(p<0.001)$.

In the geothermal therapy group, less medication use was observed ( $p=0.047, z=2.0$ ); no significant changes were observed in the music therapy or the control groups.

Adverse events during balneotherapy were assessed and registered by a GP; they were mild and transient: skin irritation (redness, rash), 4.6\% (3), and exacerbation of psoriasis, $1.5 \%$ (1). However, no patients had to discontinue treatments because of adverse events. The side effects of music therapy included headaches (3\%) (1) and annoyance due to the dislike of the music (3\%) (1).

\section{Discussion}

The results of the study demonstrated that the 2-week geothermal bath had a positive effect on stress, fatigue, mood, pain, and cognitive function, as cardiopulmonary function. Compared to music therapy, balneotherapy showed a more significant effect in reducing stress symptoms and pain and in improving the mood of the participants. When counting large-medium effect sizes, geothermal water treatment was more effective in relieving stress- and fatigue-related symptoms and pain, compared to the results of the control groups. Our study proved the safety of geothermal very high-salinity water as a treatment for the general working population.

A number of trials exploring the benefits of balneotherapy to humans have been conducted $[16,20,23,25,27]$. The combined effects of balneotherapy have been shown to result in positive outcomes related to rheumatic, skin, cardiovascular, pulmonary, endocrine, and mental diseases and in the improvement of public health [22-29, 37-39, 44-47]. However, spa medicine is not yet sufficiently recognized in psychiatry [23]. The effect of relaxation, a sense of well-being, and a reduction of stress are associated with changes in hormones like cortisol or endogenous opiates [21, 35]. Our trial results correlate with positive effects of balneotherapy related to relieving stress, pain, feelings of depression, and burnout and improving the quality of life, sleep, psychoemotional well-being, and mental activity [18, 25, 37, 45-49]. Dubois et al. provided the first research-based proof that balneotherapy was effective and well-suited for the treatment of generalized anxiety disorder. The mean change in Hamilton's total score after 8 weeks was significantly greater in the balneotherapy than in the paroxetine group ( -12 versus -8.7; $p<0.001)$; the change in the Montgomery-Asberg Depression Rating Scale was bigger in the balneotherapy group (-8.4 versus $-7 ; p=0.04)$ [44]. The 3-week trial with Lintong mineral spring water demonstrated a positive effect on tension (from 4.75 to 2.17), anger (from 2.09 to 0.88 ), fatigue (from 3.46 to 1.12 ), confusion (from 3.36 to 1.17 ), and vigor (from 15.87 to 21.71$)$ mood scores $(p<0.05)$, and the mood state of depression-dejection also showed a decreasing trend (from 0.5 to 0.36) [37]. Positive results of a 3-week spa therapy were also observed by Blasche in patients with breast cancer (improved mood and the quality of life) and occupational burnout (reduced general fatigue, distress, and increased motivation) [46]. Compared to resting and progressive muscle relaxation, balneotherapy was more beneficial with regard to subjective effects of relaxation and similarly effective with regard to a decrease in salivary cortisol levels [48]. According to the results of a study by LatorreRomán et al., 12-day balneotherapy had a positive effect on pain, mood, sleep quality, and depression in healthy older people: pain decreased by 1.2 on VAS $(p=0.001)$, depression by $0.18(p=0.03)$, anxiety by $0.38(p=0.001)$, tension by $0.37(p=0.001)$, and fatigue by $0.35(p=0.001)$, whereas vigor increased by 0.18 ( $p=0.049)$ [49].

There is a strong association between stress and pain $[2,10]$, and the analgesic effect of thermal water is wellknown and confirmed in meta-analyses and systematic reviews [23-25, 27, 50]. Naumann and Sadaghiani conducted a systematic review and meta-analysis of randomized trials on hydrotherapy and balneotherapy in fibromyalgia patients, which showed moderate evidence for a significant reduction of pain at the end of the balneotherapy treatment (standard mean difference (SMD) $-0.84 ; p=0.002)$ and for a medium improvement in the quality of life (SMD $-0.78 ; p<0.0001)$; there was no significant effect on depressive symptoms (SMD $-0.87 ; p=0.07$ ) [50]. All the reviewed studies on lower back pain reported that balneotherapy was superior in long term to tap water therapy in relieving pain and improving function and that spa therapy combining balneotherapy with mud pack therapy and/or exercise therapy, physiotherapy, and/or education was effective in the management of low back pain and superior or equally effective to the control treatments in short and long terms [51]. The various articles are exploring the importance and significance of traditional/alternative way of pain treatment with conclusion that pain is best controlled using coordinated efforts of both traditional and alternate measures [52]. Our trial demonstrated that after 2 weeks of procedures, systolic (by $7 \mathrm{mmHg}$ ) and diastolic (by $6 \mathrm{mmHg}$ ) blood pressure, as well as heart rate $(15 \mathrm{bpm})$ and 
respiratory rate (1 time/min) lowered among our subjects. This finding is in line with the results of a study conducted by $\mathrm{Xu}$ et al., demonstrating improved cardiopulmonary function after thermal baths [38] and safety of the therapy for participants with mild to moderate hypertension [33, 34, $39,47]$. Becker et al. have revealed hydrotherapy effects on lowering blood pressure, $12 \mathrm{mmHg}$ in systolic blood pressure and $26 \mathrm{mmHg}$ in diastolic blood pressure [31]; other scientists found that one mineral bath is lowering systolic blood pressure $2-15 \mathrm{mmHg}$ and reducing heart rate $5-6 \mathrm{t} / \mathrm{min}$ [53].

The ability to rest, relax, and recuperate is a form of selftreatment and an important aspect in combating the harmful effects of cumulative stress [17]. Since each person responds to stress differently, there is no single effective stress reduction strategy. Individuals may successfully achieve work- or life-related stress reduction through multidisciplinary work utilizing an integrated approach [7, 14]: organizational risk prevention $[5,8]$, changing one's mindset from "stress-isdebilitating" to "stress-is-enhancing" (which can profoundly influence psychological, behavioral, and physiological outcomes) [17], living a healthy lifestyle, and using interventions to balance or minimize stress intensity [54] with the help of population-based wellness strategies. Balneotherapy using geothermal water may be a valuable strategy to use $[23,29$, $46,48,49]$.

To our knowledge, this study is the first to explore the effect and safety of geothermal mineral water therapy with very high-salinity water. Our results showing big promises for relieving psychoneurological conditions in humans might be related to water mineralization or its origin. The limitations of our study are significant differences in certain scale dimensions between the groups that emerged during the initial stages of the study, the evaluation of the effect of the therapy on the representatives of a single profession and by a single GP, subjective measures of stress and fatigue, administration of music therapy at home, open-label trial, and no followup. The challenge for the future will be to carry out well designed studies in larger patient population with different water mineralization levels and follow-up. The results of our study results demonstrate a need for further research in balneotherapy using geothermal waters as a stress-reducing tool as well as a separate tool for disease prevention and treatment.

\section{Conclusions}

(1) Geothermal water baths reduce stress, fatigue, and pain, improve mood, stress management and cognitive functions, and have a positive effect on the cardiopulmonary system.

(2) Balneotherapy using geothermal water proved to be more efficient for relieving stress and pain than music therapy was, whereas, for all stress- and fatiguerelated conditions, it was more efficient than no therapy.

(3) Balneotherapy could be an effective measure for stress prevention and health restoration as an integral part of a multimodal work-related stress-reducing program.

\section{Ethical Approval}

Approval was obtained from Kaunas Regional Biomedical Research Ethics Committee, no. BE-2-31/2012 (Lithuania).

\section{Competing Interests}

There are no competing interests regarding this paper.

\section{References}

[1] J. L. McLauglin, Stress, fatigue and workload: determining the combined effect on human performance [Doctor Dissertation], University of Central Florida, Orlando, Fla, USA, 2007.

[2] S. Maghout-Juratli, J. Janisse, K. Schwartz, and B. B. Arnetz, "The causal role of fatigue in the stress-perceived health relationship: a MetroNet study," Journal of the American Board of Family Medicine, vol. 23, no. 2, pp. 212-219, 2010.

[3] B. M. Kudielka and S. Wüst, "Human models in acute and chronic stress: assessing determinants of individual hypothalamus-pituitary-adrenal axis activity and reactivity," Stress, vol. 13, no. 1, pp. 1-14, 2010.

[4] T. Rosenthal and A. Alter, "Occupational stress and hypertension," Journal of the American Society of Hypertension, vol. 6, no. 1, pp. 2-22, 2012.

[5] European Commission and Directorate for Employment-Social Affairs and Inclusion, Guidance on Work-Related Stress-Spice of Life or Kiss of Death? Office for Official Publications of the European Communities, Luxembourg City, Luxembourg, 2000, http://bookshop.europa.eu/is-bin/INTERSHOP.enfinity/WFS/ EU-Bookshop-Site/en_GB/-/EUR/ViewPublication-Start?PublicationKey=CE2599851.

[6] How to measure human stress, Center for studies on human stress, Ferrnand-Sequin Research Center, Canada, 2007.

[7] European Agency for Safety and Health at Work, OSH in Figures: Stress at Work. Facts and Figures, European Agency for Safety and Health at Work, Bilbao, Spain, 2009.

[8] R. Kuodytè-Kazèlienè, I. Užaitè, R. Palinauskienè, A. Kuznikovas, L. Šeryte, and R. Ulianskiené, "Prevalence of stress, depression and anxiety in healthcare and education workers in Panevezystawn," Medicinosteorijairpraktika, vol. 13, no. 4, pp. 479-484, 2007.

[9] R. T. B. Iversen, “The mental health of seafarers," International Maritime Health, vol. 63, no. 2, pp. 78-89, 2012.

[10] J. Sąlyga, "Lifestyle of Lithuanian seamen at the sea: fatigue, stress and related factors," Sveikatos Mokslai, vol. 2, pp. 1664$1669,2008$.

[11] N. A. Lysov, V. V. Goryachev, and V. Goryachev, Resort Medicine: Monography, NSEI HPE Medical Institute REAVIZ, 2013.

[12] L. Bernardi, C. Porta, G. Casucci et al., "Dynamic interactions between musical, cardiovascular, and cerebral rhythms in humans," Circulation, vol. 119, no. 25, pp. 3171-3180, 2009.

[13] HydroGlobe, "Definition of a global framework for hydrotherapy A FEMTEC-FoRSTjoint project with the cooperation of ISMH and the technical support oh WHO," Essentials from the Final Report, 2013, http://termasworld.com/documentos/ hydroglobe.pdf. 
[14] J. Burton, WHO Healthy Workplace Framework and Model: Background and Supporting Literature and Practices, World Health Organization, Geneva, Switzerland, 2010, https://osha .europa.eu/en/tools-and-publications/publications/reports/priorities-for-occupational-safety-and-health-research-in-europe2013-2020.

[15] A. Smith, P. Allen, and A. Wadsworth, Seafarer Fatigue: The Cardiff Research Programme, Cardiff University, Centre for Occupational and Health Psychology, Cardiff, UK, 2006.

[16] M. Stier-Jarmer, S. Kus, D. Frisch, C. Sabariego, and A. Schuh, "Health resort medicine in non-musculoskeletal disorders: is there evidence of its effectiveness?" International Journal of Biometeorology, vol. 59, no. 10, pp. 1523-1544, 2015.

[17] A. J. Crum, P. Salovey, and S. Achor, "Rethinking stress: the role of mindsets in determining the stress response," Journal of Personality and Social Psychology, vol. 104, no. 4, pp. 716-733, 2013.

[18] M. Sekine, A. Nasermoaddeli, H. Waqng, H. Kanayma, and S. Kagamimori, "Spa resort use and health-related quality of life, sleep, sickness absence and hospital admission: the Japanese civil servants study," Complementary Therapiesin Medicine, vol. 14, no. 2, pp. 133-143, 2006.

[19] R. McCaffrey, "Music listening: its effects in creating a healing environment," Journal of Psychosocial Nursing and Mental Health Services, vol. 46, no. 10, pp. 39-44, 2008.

[20] VŠI Lithuanian Resort Research Center, Standardized Recommendation for Mineral Water Use in Resorts for Wellness, Prevention, Treatment and Rehabilitation, VŠ́t Lithuanian Resort Research Center, Druskininkai, Lithuania, 2008.

[21] M. Toda, K. Morimoto, S. Nagasawa, and K. Kitamura, "Change in salivary physiological stress markers by spa bathing," Biomedical Research, vol. 27, no. 1, pp. 11-14, 2006.

[22] M. Gudmundsóttir, A. Brynjólfsdóttir, and A. Albertsson, "The history of the blue lagoon in Svartsengi," in Proceedings of the World Geothermal Congress, Bali, Indonesia, April 2010.

[23] F. Maraver and Z. Karagulle, Medical Hydrology and Balneology: Environmental Aspects, vol. 6 of Serie de Monografias, 2012.

[24] A. Fraioli, G. Mennuni, M. Grassi et al., "SPA treatments of diseases pertaining to internal medicine," Clinica Terapeutica, vol. 161, no. 2, pp. e63-e79, 2011.

[25] M. E. Falagas, E. Zarkadoulia, and P. I. Rafailidis, "The therapeutic effect of balneotherapy: evaluation of the evidence from randomised controlled trials," International Journal of Clinical Practice, vol. 63, no. 7, pp. 1068-1084, 2009.

[26] A. Françon and R. Forestier, "Spa therapy in rheumatology. Indications based on the clinical guidelines of the French National Authority for health and the European League Against Rheumatism, and the results of 19 randomized clinical trials," Bulletin de l'Academie Nationale de Medecine, vol. 193, no. 6, pp. 1345-1356, 2009.

[27] A. Nassermoaddeli and A. Kagamimori, "Balneotherapy in medicine: a review," Envoronmental Health and Preventive Medicine, vol. 10, no. 4, pp. 171-179, 2005.

[28] K. Horváth, Á. Kulisch, A. Németh, and T. Bender, "Evaluation of the effect of balneotherapy in patients with osteoarthritis of the hands: a randomized controlled single-blind follow-up study," Clinical Rehabilitation, vol. 26, no. 5, pp. 431-441, 2012.

[29] T. Bender, G. Bálint, Z. Prohászka, P. Géher, and I. K. Tefner, "Evidence-based hydro- and balneotherapy in Hungary-a systematic review and meta-analysis," International Journal of Biometeorology, vol. 58, no. 3, pp. 311-323, 2014.

[30] S. Tenti, A. Fioravanti, G. M. Guidelli, N. A. Pascarelli, and S. Cheleschi, "New evidence on mechanisms of action of spa therapy in rheumatic diseases," TANG Humanitas Medicine, vol. 4, no. 1, p. e3, 2014.

[31] B. E. Becker, K. Hildenbrand, R. K. Whitcomb, and J. P. Sanders, "Biophysiologic effects of warm water immersion," International Journal of Aquatic Research and Education, vol. 3, pp. 24-37, 2009.

[32] M. Vitale, "Basic sciences and balneology," in Proceedings of the European Thermal Meeting, Enghien-les-Bains, France, November 2013, http://www.europeanspas.eu/press/Post_conference_ News_European_Thermal_Meeting.

[33] M. Oláh, A. Koncz, J. Fehér et al., "The effect of balneotherapy on C-reactive protein, serum cholesterol, triglyceride, total antioxidant status and HSP-60 levels," International Journal of Biometeorology, vol. 54, no. 3, pp. 249-254, 2011.

[34] M. Oláh, Á. Koncz, J. Fehér et al., "The effect of balneotherapy on antioxidant, inflammatory, and metabolic indices in patients with cardiovascular risk factors (hypertension and obesity) a randomised, controlled, follow-up study," Controlled Clinical Trials, vol. 32, no. 6, pp. 793-801, 2011.

[35] S. Baroni, D. Marazziti, G. Concoli, M. Piccheti, M. CatenaDell'osso, and A. Galassi, "Modulation of the platelet serotonin transporter by thermal balneotherapy: a study in healthy subjects," European Review for Medical and Pharmacological Sciences, vol. 16, pp. 589-593, 2012.

[36] K. Yamamoto, Y. Aso, S. Nagata, K. Kasugai, and S. Maeda, "Autonomic, neuro-immunological and psychological responses to wrapped warm footbaths-a pilot study," Complementary Therapies in Clinical Practice, vol. 14, no. 3, pp. 195-203, 2008.

[37] L. Xu, R. Shi, B. Wang et al., "Effect of 3 weeks of balneotherapy on immunological parameters, trace metal elements and mood states in pilots," Journal of Physical Therapy Science, vol. 25, no. 1, pp. 51-54, 2013.

[38] L. Xu, R. Shi, B. Wang et al., "21-day balneotherapy improves cardiopulmonary function and physical capacity of pilots," Journal of Physical Therapy Science, vol. 25, no. 1, pp. 109-112, 2013.

[39] A. Kapetanovic, S. Hodžic, and D. Advic, “The effect of mineral radon water applied in the form of full baths on blood pressure in patients with hypertension," Journal of Health Sciences, vol. 3, no. 1, pp. 38-40, 2013.

[40] P. Hubner, "Medical Resonance Therapy Music," General Stress Symptoms Medical Music Program, http://www.dynamicspacestereophony.com/ScientificResearch/science.php?track=10001099.

[41] T. A. Badger, C. Segrin, and P. Meek, "Development and validation of an instrument for rapidly assessing symptoms: the general symptom distress scale," Journal of Pain and Symptom Management, vol. 41, no. 3, pp. 535-548, 2011.

[42] A. J. Dittner, S. C. Wessely, and R. G. Brown, "The assessment of fatigue. A practical guide for clinicians and researchers," Journal of Psychosomatic Research, vol. 56, no. 2, pp. 157-170, 2004.

[43] D. E. Broadbent, P. F. Cooper, P. FitzGerald, and K. R. Parkes, "The cognitive failures questionnaire (CFQ) and its correlates," British Journal of Clinical Psychology, vol. 21, no. 1, pp. 1-16, 1982.

[44] O. Dubois, R. Salamon, C. Germain et al., "Balneotherapy versus paroxetine in the treatment of generalized anxiety 
disorder," Complementary Therapies in Medicine, vol. 18, no. 1, pp. 1-7, 2010.

[45] M. Secher, M. Soto, S. Gillette et al., "Balneotherapy, prevention of cognitive decline and care the Alzheimer patient and his family: Outcome of a multidisciplinary workgroup," Journal of Nutrition, Health and Aging, vol. 13, no. 9, pp. 797-806, 2009.

[46] G. Blasche, "Association of spa therapy with improvement of psychological symptoms of occupational burnout," Forschende Komplementärmedizin, vol. 17, no. 3, pp. 132-136, 2010.

[47] L. M. Iashina, L. E. Shatrova, K. S. Zhdanova, and T. A. Kuznetsova, "The influence of radon baths on the lipid profi le of patients with cardiovascular diseases and dyslipidemia," Voprosy Kurortologii, Fizioterapii, I Lechebnoй Fizicheskoй Kultury, no. 2, pp. 3-4, 2011.

[48] F. Matzer, E. Nagele, B. Bahadori, K. Dam, and C. Fazekas, "Stress-relieving effects of short-term balneotherapy-a randomized controlled pilot study in healthy adults," Forschende Komplementarmedizin, vol. 21, no. 2, pp. 105-110, 2014.

[49] P. Á. Latorre-Román, M. Rentero-Blanco, J. A. Laredo-Aguilera, and F. García-Pinillos, "Effect of a 12-day balneotherapy programme on pain, mood, sleep, and depression in healthy elderly people," Psychogeriatrics, vol. 15, no. 1, pp. 14-19, 2015.

[50] J. Naumann and C. Sadaghiani, "Therapeutic benefit of balneo therapy and hydro therapyinthe management of fibromyalgia syndrome: a qualitative systematic reviewand meta-analysis of randomized controlledtrials," Arthritis Research \& Therapy, vol. 16, no. 4, article R141, 2014.

[51] M. Karagülle and M. Z. Karagülle, "Effectiveness of balneotherapy and spa therapy for the treatment of chronic low back pain: a review on latest evidence," Clinical Rheumatology, vol. 34, no. 2, pp. 207-214, 2015.

[52] H. Khan, B. Eto, V. De Feo, and A.-U.-H. Gilani, "Evidence based alternative medicines in pain management," EvidenceBased Complementary and Alternative Medicine, vol. 2015, Article ID 313821, 2 pages, 2015.

[53] E. V. Vladimirsky and T. N. Filtsagina, "The problems of antihypertensive balneotherapy," Voprosy Kurortologii, Fizioterapii, I Lechebno ̌ Fizicheskoй Kultury, no. 5, pp. 40-45, 2013.

[54] L. O. Fjorback, "Mindfulness and bodily distress," Danish Medical Journal, vol. 59, no. 11, Article ID B4547, 2012. 


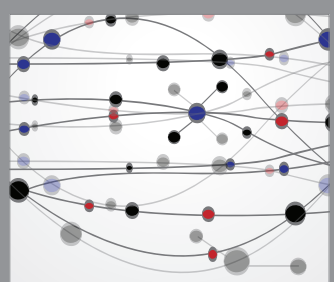

The Scientific World Journal
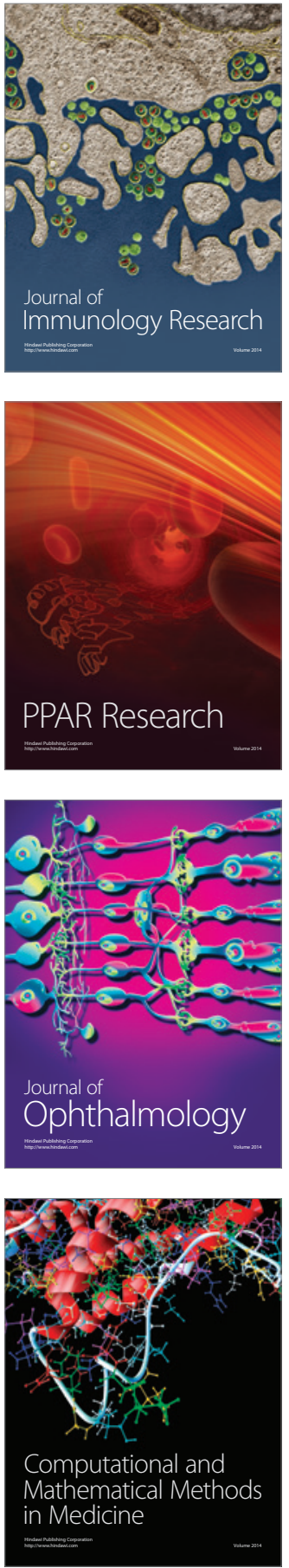

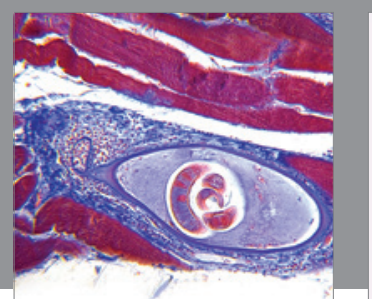

Gastroenterology Research and Practice

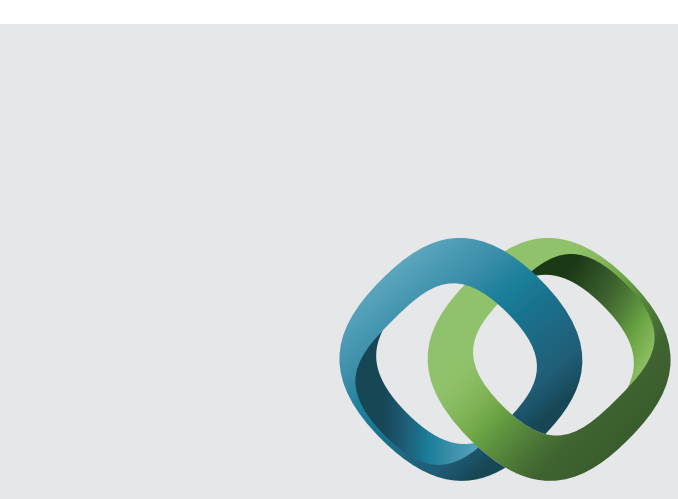

\section{Hindawi}

Submit your manuscripts at

http://www.hindawi.com
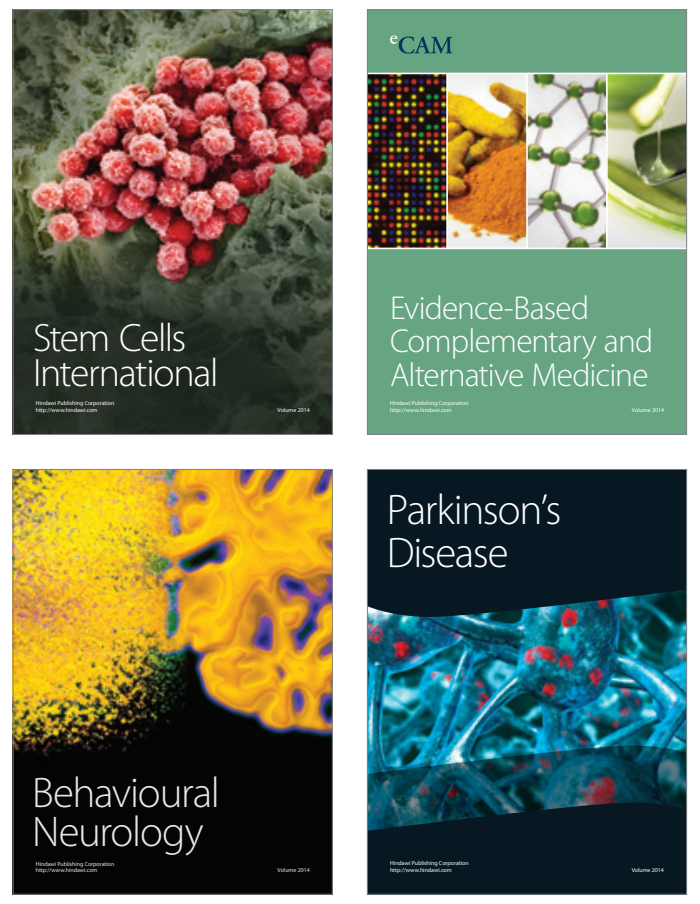
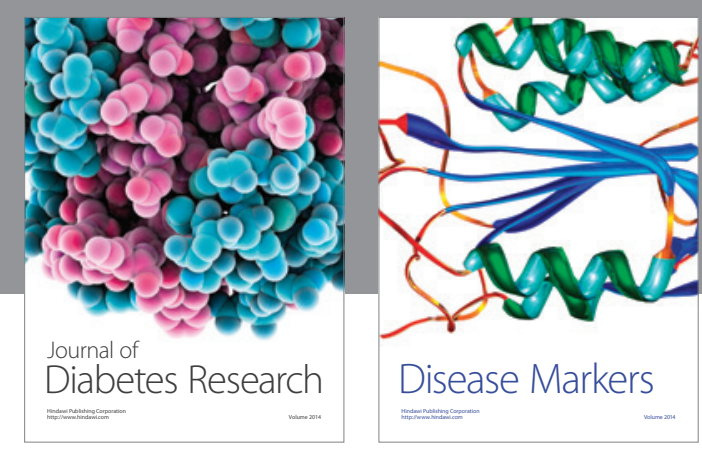

Disease Markers
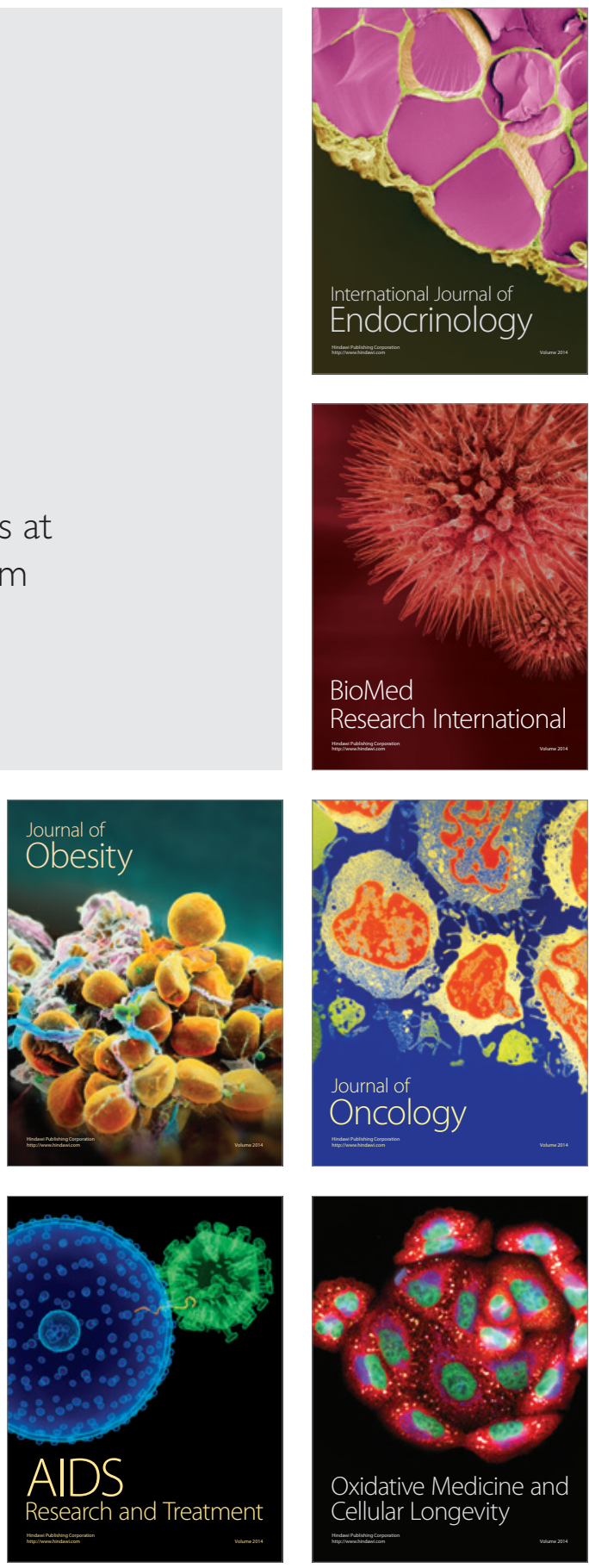